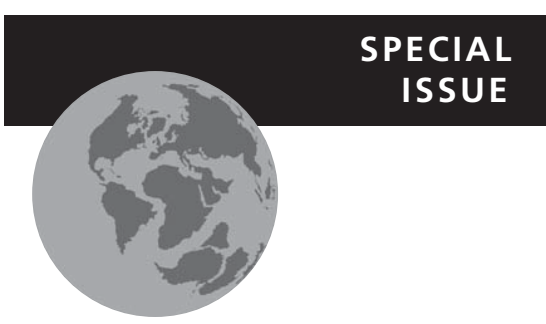

\title{
On the island biogeography of aliens: a global analysis of the richness of plant and bird species on oceanic islands
}

Tim M. Blackburn ${ }^{1,2,3,4,5 *}$, Steven Delean ${ }^{5}$, Petr Pyšek ${ }^{6,7}$ and Phillip Cassey ${ }^{5}$

${ }^{1}$ Department of Genetics, Evolution and Environment, Centre for Biodiversity and Environment Research, Darwin Building, UCL, Gower Street, London WC1E 6BT, UK, ${ }^{2}$ Institute of Zoology, Zoological Society of London, Regent's Park, London NW1 4RY, UK, ${ }^{3}$ Distinguished Scientist Fellowship Program, King Saud University, Riyadh 1145, Saudi Arabia, ${ }^{4}$ Department of Botany and Zoology, Centre for Invasion Biology, Stellenbosch University, South Africa, ${ }^{5}$ School of Biological Sciences and the Environment Institute, The University of Adelaide, Adelaide, SA 5005, Australia, ${ }^{6}$ Department of Invasion Ecology, Institute of Botany, The Czech Academy of Sciences, CZ-252 43 Průhonice, Czech Republic, ${ }^{7}$ Department of Ecology, Faculty of Science, Charles University in Prague, Viničná 7, CZ-128 44 Praha 2, Czech Republic

\footnotetext{
${ }^{*}$ Correspondence: Tim M. Blackburn, Department of Genetics, Evolution and Environment, Centre for Biodiversity and Environment Research, Darwin Building, UCL, Gower Street, London WC1E 6BT, UK. E-mail: t.blackburn@ucl.ac.uk
}

\begin{abstract}
Aim (1) To characterize the relationship(s) between species richness and area for alien plant and bird species on islands, and to identify commonalities and differences in those relationships for these different taxa, and between alien and native species; (2) to test whether area per se, native species richness or human factors related to area is the primary determinant of alien species richness; and (3) to explore the effects on alien island biogeography of isolation, productivity and the time since first European landfall.
\end{abstract}

Location Islands around the world.

Methods We used structural equation models (SEMs; supported by generalized linear models) to interrogate data on the alien and native species richness of birds and plants on islands.

Results Alien plant and bird species richness were both strongly correlated with island area, with similar slopes on logarithmic axes. SEMs for both plants and birds revealed positive direct effects of native species richness and human population size, and positive indirect effects of area, on alien species richness. The models also identified indirect effects of temperature (positive) and isolation (negative) on alien species richness. Native plant and bird species richness were both predicted by direct effects of area (positive), temperature (positive) and isolation (negative). However, native plant richness was the only direct predictor of native bird species richness, and the strongest direct predictor of alien bird species richness, for islands with both plant and bird richness data.

Main conclusions Our analyses recover the species-area, species-isolation and productivity relationships in native richness. Alien species richness was most strongly related to native species richness, with additional effects of human population size. Human population size most likely determines the number of alien species that arrive on an island, while the effect of native species richness may be driven by the influence of habitat heterogeneity on the likelihood that those populations persist (establishment success).

\section{Keywords}

Alien species, birds, human population size, island biogeography, native species richness, plants, species-area relationship, structural equation model.

\section{INTRODUCTION}

Species richness shows substantial spatial variation, but all such variation is the result of the interaction of four key processes: immigration, emigration, speciation and extinction. There is a large body of published research devoted to understanding exactly why these processes vary over space and time, and how they interact to determine species richness (see reviews in Rosenzweig, 1995; Whittaker, 1998; Kalmar \& Currie, 2006). Much of this work has focused on variation in species richness across islands, especially since the publication of the seminal work by MacArthur \& Wilson (1967) on island biogeography. 
Islands constitute well-defined but restricted spatial units, which make ideal natural laboratories for studying the processes that lead to different numbers of species inhabiting different spatial locations.

Species richness on islands shows several consistent patterns of variation (Whittaker, 1998; Kreft et al., 2008; Whittaker et al., 2008; Triantis et al., 2012) and (all else being equal) is higher: (1) on larger islands (the species-area relationship), (2) on islands with higher primary productivity, (3) on islands closer to the continental mainland, (4) on land-bridge islands than on oceanic islands, and (5) on geologically older islands than on younger islands, although richness can decline again with age on very old islands. The caveat of 'all else being equal' here includes the geological and evolutionary history of the islands, the taxon concerned and the interaction of different features (e.g. size versus isolation). Nevertheless, on average, we expect larger, older (but not too old), less isolated, more productive, landbridge islands to be home to more species.

These consistent patterns have in turn led to a variety of hypotheses regarding how the processes of immigration, emigration, speciation and extinction may act to determine island species richness. However, while islands make excellent natural laboratories, using them to test different hypotheses for observed patterns in species richness is difficult: the processes concerned are not readily amenable to controlled experimental manipulation, while tests of different predictions using observational data on richness patterns are unlikely to be clear-cut. Given these issues, one potentially valuable opportunity to study the processes underlying island species richness patterns is to exploit the large-scale experiment in nature that is provided by alien species. A recent upsurge of interest in the island biogeography of alien species has followed from the observation that they may provide valuable information on the natural processes structuring the assemblage of island biotas (Brown \& Sax, 2004; Sax \& Gaines, 2005; Blackburn et al., 2008).

Alien species are species whose presence in a region is attributable to human actions, which have enabled them to overcome fundamental biogeographical boundaries (Blackburn et al., 2011; Richardson et al., 2011). Their species richness will therefore be determined by human factors, but potentially also in part by the same natural processes that determine native species richness. We might expect quantitatively similar relationships in the island biogeography of native and alien species if assemblages of both sets of species are responding to common structuring processes, but differences where those structuring processes differ (Hulme, 2008). For example, Blackburn et al. (2008) found that alien bird species on 41 islands and archipelagos world-wide had a species-area relationship (log-log axes) of similar slope ( $z=0.18$ vs. 0.25 ) but lower intercept ( $c=0.18$ vs. 0.79 ) than that for native bird species from the same locations. The relationships between species richness and isolation from the nearest continental mainland were weakly (and not significantly) negative for native bird species but significantly positive for aliens. Taken at face value, this might suggest that common processes determine the slopes of native and alien species-area relationships (e.g. common extinction processes acting on established populations), while different processes determine their intercepts and the forms of species-isolation relationships (e.g. the different drivers of immigration in natives versus aliens). However, at present it is difficult to draw conclusions about the generality of different processes as determinants of alien species richness on islands, as few studies have tested alternative hypotheses for these patterns. Those that have have tended to compare measures of three potential correlates of richness: island area, native species richness and human population size.

Island area is a convenient surrogate for the same area-related natural processes that determine native species richness. For example, extinction probability is thought to be higher on smaller islands, as these tend to house smaller populations more likely to be affected by demographic and environmental stochasticity, or Allee effects; such effects will apply equally to both native and alien species. Nevertheless, some natural processes are unlikely to influence alien species richness, including anything linked to the rate or magnitude of speciation. The influence of island area may therefore be altered depending on the extent to which these processes underlie species-area relationships.

Native species richness may be positively or negatively related to alien species richness. Islands rich in native species may limit the establishment of alien species through negative biotic interactions such as competition or predation (termed biotic resistance; Elton, 1958). Conversely, areas that can support many native species may also be able to support many alien species, leading to positive relationships between native and alien species richness ('the rich get richer', sensu Stohlgren et al., 2003). Such relationships might be expected if a key restriction on native species richness is dispersal limitation, such that total species richness can increase markedly if this limitation is overcome by the anthropogenic movement of species (Hulme, 2009). Native species richness may also affect human responses to alien species, for example if depauperate native biotas have stimulated intentional efforts to increase local biodiversity for hunting or aesthetic reasons.

Finally, given that the presence of alien species is attributable to human actions, a range of factors relating to the magnitude of human impacts in an area might influence alien species richness. For example, the volume of trade to an island (often analysed in terms of gross domestic product, GDP) may determine the number of species deliberately or accidentally imported (i.e. human-mediated immigration), whereas the extent of anthropogenic habitat modification might relate to the opportunities for alien species to establish viable populations. Many of these factors will correlate strongly with human population size (e.g. Kummu \& Varis, 2011), which is therefore a convenient surrogate for human influence on alien species richness. Since most movements of alien species have occurred in the period since Europeans started to navigate and explore the globe ( $\mathrm{di}$ Castri, 1989; Hulme, 2009), the time since the first European landfall may also relate positively to the number of species that have had the opportunity to colonize an island (Blackburn et al., 2008). 
Different empirical studies of the richness of alien species on islands have found different effects of human factors, area and native species richness, for both plants (e.g. Lonsdale, 1999; Sax et al., 2002; Long et al., 2009; Kueffer et al., 2010; Pretto et al., 2012) and animals (e.g. Case, 1996; Chown et al., 1998; Sax et al., 2002; Blackburn et al., 2008; Ficetola \& Padoa-Schioppa, 2009). The increasing number of studies of alien species richness on islands, and the lack of consistent comparisons or outcomes from them, suggests to us that a synthetic analysis of available data would be timely. Therefore, here we compile and analyse data on the richness of plant and bird species derived from previous studies from oceanic islands world-wide. We focus on plants and birds because data for both native and alien species richness are available from a large number of islands, relative to other taxa.

Our aims were threefold. First, we wished to characterize the relationship(s) between species richness and area for alien species, to identify commonalities and differences in the relationships for different taxa, and between alien and native species. Second, we wanted to test for the effects of different drivers of area-related variation in alien species. Specifically, we were interested in whether area per se is a primary determinant of alien species richness or whether native species richness or human factors related to area underlie variation in alien species richness across islands. We also collated information on the isolation of islands from mainland regions, metrics of productivity and the time since first European landfall on an island. As pointed out above, isolation and productivity have been shown to be key determinants of native species richness on oceanic islands. Time since first European landfall may influence alien richness independently of area-related effects. Our third aim was to explore the effects of these additional factors on alien species richness. The synthetic approach allows us to test these different hypotheses across broader ranges of variation than has been possible before, which may allow us to extract some generalities despite the range of outcomes from previous studies.

\section{METHODS}

We analysed data on the alien and native species richness of birds from 68 island locations and on plants from 62 island locations around the world. This represents a total of 90 islands, of which 40 included data for both taxa. Some locations represent single islands, and some whole archipelagos, but each individual island is included in each taxon dataset only once. Locations were distributed within the Atlantic $(n=14)$, Caribbean $(n=7)$, Indian $(n=12)$, Pacific $(n=37)$ and Southern $(n=20)$ oceans. We only included data for islands $>90 \mathrm{~km}$ from a continental mainland, so that as much as possible we are considering oceanic islands (in effect, if not necessarily in geological origin). Alien species richness refers to naturalized or established species from sources published since 1995 (to minimize variation in numbers due to time available to establish). For birds, native species richness refers to terrestrial species breeding on the island, including recently extinct species (since AD 1500).
In addition to species richness, we obtained the following data for all islands in the data set: area $\left(\mathrm{km}^{2}\right)$, distance from the nearest continental mainland $(\mathrm{km})$, distance from the nearest landmass larger than the island/archipelago $(\mathrm{km})$, temperature $\left({ }^{\circ} \mathrm{C}\right)$, precipitation $(\mathrm{mm})$, latitude (degrees from the Equator), time since first European arrival (2013 minus the date of first European landing if possible, otherwise the first sighting or first attempt to colonize) and human population size. Data on temperature and precipitation were obtained from Mitchell \& Jones (2005). Distances were calculated using the Google Maps Distance Measurement tool. Other data were sourced from internet fact pages including the CIA Factbook and Wikipedia (or linked references in a few cases). The data and sources are available in Appendix S1 in Supporting Information. We use natural logarithm transforms (hereafter, log) of alien and native species richness, island area, human population size, distance from land and time since colonization variables for all statistical analyses.

We used a structural equation model (SEM; Grace, 2006) to investigate direct and indirect effects of island area, human population size, latitude, environment (temperature and precipitation), distance from land (nearest larger island and nearest continental land mass) and time since European colonization on alien and native species richness on islands. In addition to alien and native species richness, the hypothesized interrelationships among the variables resulted in human population size and the environment variables (temperature and precipitation) also being treated as endogenous (i.e. response) variables in our model. We used the SEM to partition the correlations between the exogenous explanatory variables and endogenous response variables into direct and indirect effects using a recursive path analysis (Grace, 2006).

We developed our SEM model a priori based on hypothesized relationships from theoretical and empirical evidence (Fig. S1 in Appendix S2). We were specifically interested in evaluating the relative importance of native species richness, island area and human population size on alien species richness. However, the SEM approach allowed simultaneous testing of theoretical native species-area relationships and the hypothesized effects of biogeographical, environmental and historical variables on both alien and native species richness. We also assessed relationships between human population size and island area and biogeography within the model. We tested for differences in SEM path relationships between birds and plants by contrasting a model having additive taxon effects with a model where relationships differed between taxon groups, using the Bayesian information criterion (BIC).

We assessed the fit of our theoretical SEM using a $\chi^{2}$ goodness-of-fit test of the difference between the observed data and hypothesized model, the root mean square error of approximation (RMSEA) and the comparative fit index (CFI). A satisfactory model fit was indicated by: (1) a non-significant $\chi^{2}$ goodness-of-fit test ( $\alpha=0.05$ ), (2) CFI $>0.9$, and (3) lower $90 \%$ confidence intervals (CIs) of RMSEA $<0.05$ (Zhang et al., 2013). In the case of poor model fit, we used large residual covariances and high modification indices (and/or standardized expected parameter change values) to identify missing paths or 
residual correlations and to respecify the model. A parametric bootstrap approach was used to estimate $95 \%$ CIs of path coefficients (direct and indirect) and derived estimates of total effects (i.e. the sum of direct and indirect effects). After identifying an adequate respecified SEM (based on our criteria above; Table S1 in Appendix S2), we simplified the model by removing terms with direct path coefficients for which their bootstrap 95\% CIs included zero.

The SEM approach has the advantage of estimating the (total) effects of the explanatory variables on the multiple response variables simultaneously (and additionally assesses the relationships between response variables). However, with this approach we are forced to logarithmically transform the species richness variables (which are counts) prior to the analysis (including the addition of +1 to those variables that take zero values). Therefore, we also analysed the data using a set of independent hypothesis-specific generalized linear models (GLMs). These models are fitted using a negative binomial variance function and $\log$ link, and hence properly account for the variation (including overdispersion) of the count variables. We include the results of the more conservative GLM approach in Appendix S2 to support the SEM findings.

Kissling et al. (2008) found, using SEM, that native plant species richness affects native bird species richness in Kenya. Therefore, we further examined how relationships between native and alien bird species richness were associated with native plant species richness, using the subset of islands ( $n=40)$ for which both bird and plant species richness data were available. We used the final path model identified for bird species richness relationships from the full data set as a starting model, and included the following additional sets of paths: (1) exogenous paths for the effects of native plant species richness on both native and alien bird species richness endogenous variables, and (2) exogenous paths for the effects of island area, temperature and distance to the nearest continental mainland on native plant species richness (as identified for native plant species richness relationships from models fitted to the full data set). The full SEM model for this analysis is presented in Fig. S2 in Appendix S2, and was simplified as described above.
All statistical analyses were conducted using R 3.1.0 (R Core Team, 2014). The SEMs were calculated with the $\mathrm{R}$ package lavaan 0.5-16 (Rosseel, 2012).

\section{RESULTS}

Figure 1 shows the species-area relationships for alien and native plant and bird species on oceanic islands around the world. Both alien plant and alien bird species-area relationships have slopes $(z)$ that are statistically indistinguishable, and that are also indistinguishable from 0.25 , which is often cited as the canonical slope for native island species-area relationships [plants, $z(95 \% \mathrm{CI})=0.24(0.15-0.33)$; birds, $z=0.27(0.17-$ $0.36)]$. Native plant and bird species-area relationships also have statistically indistinguishable slopes, but these are steeper than those for the alien species in the same taxon, with CIs that do not overlap 0.25 [plants, $z=0.39(0.32-0.46)$; birds, $z=0.36(0.28-0.43)]$.

The comparison between full SEM path models with additive taxon effects and independent models, where the relationships differed between taxa, suggested that the latter were more likely given the data $(\triangle \mathrm{BIC}=133.4)$. Model simplification for each taxon (described in Appendix S2) resulted in the models presented in Fig. 2. The standardized coefficient estimates relating to each path in these figures are also given in Table 1 .

The SEM path model for alien bird species richness identified strong positive direct effects of both human population size and native bird species richness (Fig. 2a, Table 1). There was also a negative direct effect of precipitation. The effect of island area on alien bird species richness was indirect, acting through the positive effects of area on native species richness and human population size. The standardized effect sizes of human population size, native bird species richness and island area were all of similar magnitude, albeit that the effect of area was indirect. There was also an indirect positive effect of temperature, and an indirect negative effect of distance from the nearest continent, on alien bird species richness (Fig. 2a, Table 1). The indirect effect of temperature acted through its positive effects on native species richness and human population size, while the indirect effect of distance from the nearest continent acted through its

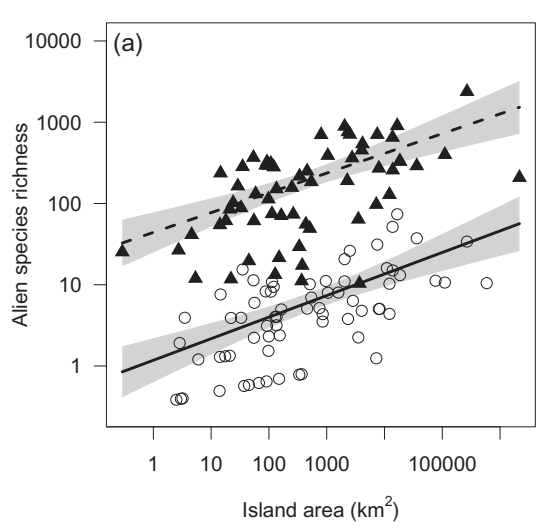

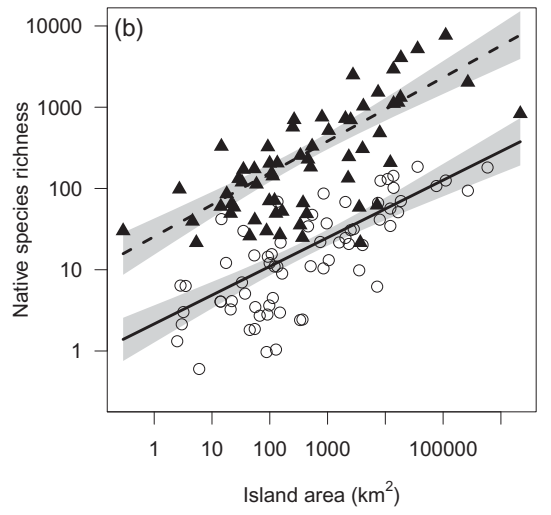

Figure 1 Model-fitted estimates of the species-area relationship for (a) alien (plants, $\log S=3.79+0.24 \log A$; birds, $\log S=0.16+0.27 \log \mathrm{A}$ ) and (b) native species richness (plants, $\log S=3.24+0.39 \log A$; birds, $\log S=0.77+0.36 \log A$ ) for each taxon. The dashed line shows the relationship for plants and the solid line for birds; points show partial deviance residuals for birds (circles) and plants (triangles). Grey shading shows $95 \%$ confidence intervals. 

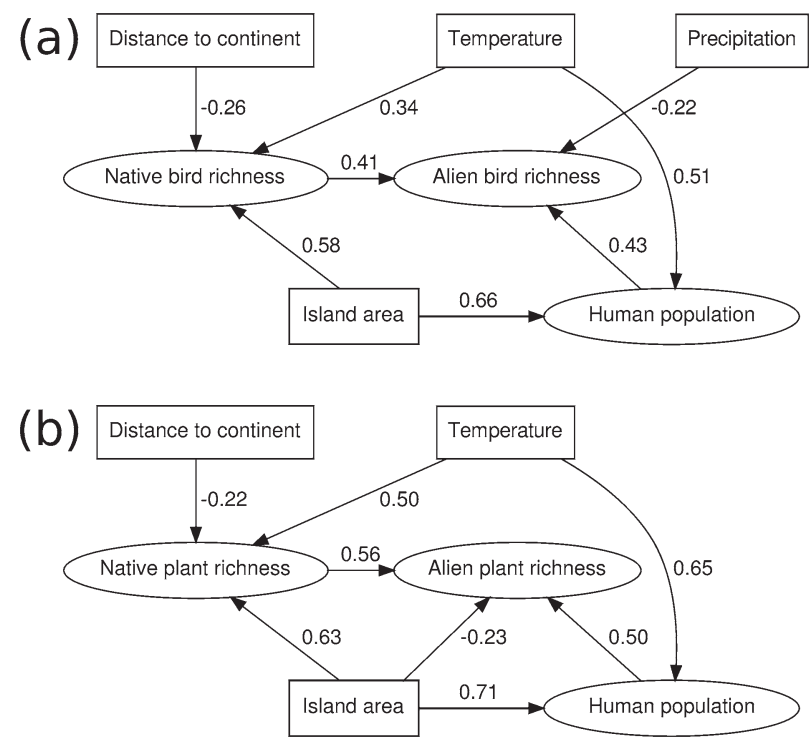

Figure 2 Simplified path analysis model for (a) bird and (b) plant species richness after excluding paths with parametric bootstrap 95\% confidence intervals that include zero. Endogenous variables are shown in ellipses and exogenous variables in rectangles; arrows indicate the direction of effects. The model $r^{2}$ values for each endogenous variable are: (a) log alien species richness $=0.61, \log$ native species richness $=0.77, \log$ human population size $=0.84$; (b) $\log$ alien species richness $=0.70, \log$ native species richness $=0.65, \log$ human population size $=0.81$. Standardized path coefficient estimates from the models are shown for each path.

negative effect on native species richness (Table 1). Thus, bird native species richness was predicted by positive direct effects of area and temperature, and a negative direct effect of distance from the nearest continent. Human population size was predicted by positive direct effects of area and temperature (Table 1). Each model term contributed either a direct or indirect effect only as their total contribution to the simplified SEM path model.

The SEM path model for alien plants was similar to that for birds, but differed in including a small direct negative effect of island area, and in lacking an effect of precipitation, on alien plant species richness (Fig. 2b, Table 1). Each model term contributed either a direct or an indirect effect only as its total contribution to the simplified SEM path model, apart from the effect of island area on alien plant species richness: the total effect of area was 0.471 (95\% CI 0.288-0.629). The total standardized effect sizes of human population size, native plant species richness and island area were all of similar magnitude, as for birds. However, the largest direct effect on alien plant species richness in the model was that of native plant species richness, versus human population size for alien bird species richness (Table 1). The indirect positive effect of temperature on alien plant species richness was stronger than the equivalent effect for birds, with only marginally overlapping CIs (Table 1). This stronger indirect effect of temperature was the result of stronger direct positive effects of temperature on native species richness and human population size in the plant model. The paths and their associated coefficients for native species richness and human population size were otherwise very similar for the bird and plant models (Fig. 2, Table 1).

The results of the GLM analysis were consistent with the SEM analysis. GLMs identified strong effects of native species richness, human population size and island area on alien bird and plant species richness, in models that treated each of these predictor variables separately (Tables S3-S5, Fig. S3 in Appendix S2). Across the three model sets for alien species richness, the best supported models were those that included native species richness as a predictor (Table S6 in Appendix S2). Effects of taxon, precipitation and temperature are also consistently included in the most likely models, along with interactions between taxon and the continuous predictor variables. The most likely model in terms of human population size included a negative effect of time since European colonization and its interaction with taxon (more recently colonized islands have more alien bird species, but alien plant species richness is independent of colonization time), but these effects were only included in two of the 12 models with AICc within 4 of the most likely model (Table S4 in Appendix S2). The most likely model set for native species richness included effects of area, taxon, temperature and precipitation, with the best-supported model including all these variables except precipitation (Tables S7 \& S8, Fig. S4 in Appendix S2).

For the subset of 40 islands with data on both plant and bird species, the simplified SEM showed that native plant species richness was strongly positively correlated with alien bird species richness (Fig. 3, Table 2), and indeed replaces the effects of native bird species and human population size identified from the taxon-specific analysis of the full data set (Fig. 2). The species-area relationship for native plants was retained in this model, but a strong positive effect of native plant species richness on native bird species richness negated the influence of island area on the latter (Fig. 3, Table 2). In addition, the direct effects of temperature and distance to the nearest continental mainland on native bird species richness were replaced by indirect effects through native plant richness. Indeed, aside from a negative direct effect of precipitation on alien bird species richness, the only direct effects on native or alien bird species richness in the simplified model are effects of native plant richness (Fig. 3, Table 2).

\section{DISCUSSION}

The positive relationship between the area of an island and the number of native species found there is one of the canonical relationships in ecology (Rosenzweig, 1995; Whittaker, 1998). The relationship is not restricted to native species. We found that alien species richness also increases with island area, for both plants and birds (Fig. 1a), as has been shown elsewhere (e.g. Case, 1996; Blackburn et al., 2008; Ficetola \& Padoa-Schioppa, 2009; Long et al., 2009; Kueffer et al., 2010). The existence of an alien species-area relationship has raised the hope that similarities and differences between this and native species-area relationships could provide valuable insight into 
Table 1 Structural equation model standardized path coefficient estimates for the simplified model for each taxon. Numbers in parentheses are 95\% parametric bootstrap confidence intervals. Indirect effects are composite effects of all indirect paths in the model for each exogenous variable. Using the simplified model, each model term contributed either a direct or an indirect effect only as a total contribution. The single exception to this was that island area contributed both directly and indirectly (through its effect on native species richness) to plant alien species richness; the total effect was 0.471 ( $95 \%$ confidence intervals, $0.288-0.629)$. 'Not included' indicates that the term was not included in the simplified model for that particular taxon.

\begin{tabular}{|c|c|c|c|c|c|}
\hline \multicolumn{2}{|l|}{ Taxon } & \multicolumn{2}{|l|}{ Birds } & \multicolumn{2}{|l|}{ Plants } \\
\hline Endogenous & Exogenous & Direct & Indirect & Direct & Indirect \\
\hline \multirow{7}{*}{$\begin{array}{l}\text { Alien species } \\
\text { richness }\end{array}$} & Area & & $0.518(0.404-0.617)$ & $-0.234(-0.427$ to -0.038$)$ & $0.705(0.541-0.886)$ \\
\hline & Human population & $0.428(0.190-0.647)$ & & $0.495(0.282-0.697)$ & \\
\hline & Native richness & $0.411(0.169-0.632)$ & & $0.561(0.365-0.747)$ & \\
\hline & Precipitation & $-0.223(-0.381$ to -0.066$)$ & & Not included & \\
\hline & Temperature & & $0.359(0.258-0.459)$ & & $0.600(0.457-0.729)$ \\
\hline & Distance to & & $-0.107(-0.197$ to -0.035$)$ & & $-0.125(-0.242$ to -0.037$)$ \\
\hline & continent & & & & \\
\hline \multirow{3}{*}{$\begin{array}{l}\text { Native species } \\
\text { richness }\end{array}$} & Area & $0.577(0.450-0.697)$ & & $0.630(0.465-0.771)$ & \\
\hline & Temperature & $0.338(0.213-0.470)$ & & $0.496(0.341-0.654)$ & \\
\hline & $\begin{array}{l}\text { Distance to } \\
\text { continent }\end{array}$ & $-0.261(-0.393$ to -0.124$)$ & & $-0.224(-0.381$ to -0.072$)$ & \\
\hline \multirow{2}{*}{$\begin{array}{l}\text { Human population } \\
\text { size }\end{array}$} & Area & $0.657(0.545-0.758)$ & & $0.710(0.574-0.848)$ & \\
\hline & Temperature & $0.514(0.408-0.629)$ & & $0.649(0.509-0.797)$ & \\
\hline
\end{tabular}

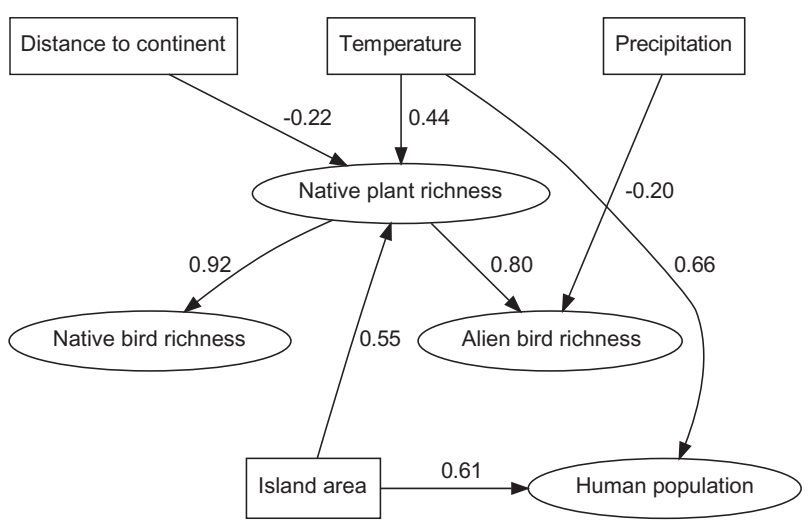

Figure 3 Simplified path analysis model (after excluding paths with parametric bootstrap 95\% confidence intervals that include zero) for bird species richness including plant species richness as an endogenous variable, for the subset of islands for which both plant and bird richness data were available. Endogenous variables are shown in ellipses and exogenous variables in rectangles; arrows indicate the direction of effects. Standardized path coefficient estimates from the models are shown for each path.

the causes of the latter. However, any such insight depends on us also understanding why there are more alien species on larger islands. Our results provide some relevant information in this regard.

Previous studies of spatial variation in alien species richness have generally considered it in terms of one or more of land area, native species richness or a measure of human activity such as human population size (but see, e.g., McKinney, 2006). These variables are intercorrelated in our data, which motivated our approach of using a SEM to explore their effects simultaneously. The SEM models of the full data set reveal that all three of these variables have positive effects on both plant and bird alien species richness, but that the effects of native species richness and human population size are direct while the effect of area is largely indirect (Fig. 2, Table 1). The SEM analyses identified strong effects of area, distance to the nearest continental landmass and temperature on native species richness (Fig. 2, Table 1), such that they recover the well-known species-area relationship, species-isolation relationship and latitudinal/ productivity gradient in species richness (see Introduction). These outcomes give us confidence that our results for alien species are also likely to be sensible, as do the relatively high goodness-of-fit values $\left(r^{2}\right)$ for each endogenous variable in both models (Fig. 2). Our results imply that alien species-area relationships arise because the area of an island influences the number of native species and the number of humans that inhabit it.

Alien species introductions are ultimately a consequence of human activities. Islands with more people should generate more trade and more transport interchange with mainland areas, all else being equal, producing more opportunities to import (and export) novel species (Pyšek et al., 2010). The strong positive path linking human population size to alien species richness in both plant and bird models (Table 1) confirms this expectation. In addition to this effect, however, areas rich in native plants are also rich in alien plants, and likewise for birds (Tables 1 \& 2; see also Lonsdale, 1999; Sax et al., 2002). This suggests that, at larger spatial scales, external factors affect the richness of native and alien species in the same way, and provides little support for the action of biotic resistance, whereby islands rich in native species resist the establishment of alien species (e.g. Elton, 1958). Rather, rich islands get richer (cf. Stohlgren et al., 2003). Thus, it appears that the alien species richness of islands is produced by a combination of 
Table 2 Structural equation model standardized path coefficient estimates for the simplified model of bird-plant inter-relationships. Numbers in parentheses are $95 \%$ parametric bootstrap confidence intervals. Indirect effects are composite effects of all indirect paths in the model for each exogenous variable.

\begin{tabular}{|c|c|c|c|}
\hline Endogenous & Exogenous & Direct & Indirect \\
\hline \multirow[t]{5}{*}{ Alien bird species richness } & Island area & & $0.441(0.284-0.606)$ \\
\hline & Precipitation & $-0.196(-0.393$ to -0.015$)$ & \\
\hline & Temperature & & $0.350(0.198-0.501)$ \\
\hline & Distance to continent & & $-0.179(-0.328$ to -0.018$)$ \\
\hline & Native plant richness & $0.798(0.659-0.897)$ & \\
\hline \multirow[t]{4}{*}{ Native bird species richness } & Island area & & $0.509(0.339-0.686)$ \\
\hline & Temperature & & $0.405(0.236-0.561)$ \\
\hline & Distance continent & & $-0.207(-0.380$ to -0.022$)$ \\
\hline & Native plant richness & $0.922(0.862-0.958)$ & \\
\hline \multirow[t]{3}{*}{ Native plant species richness } & Island area & $0.552(0.366-0.740)$ & \\
\hline & Temperature & $0.439(0.259-0.615)$ & \\
\hline & Distance continent & $-0.224(-0.409$ to -0.023$)$ & \\
\hline \multirow[t]{2}{*}{ Human population size } & Island area & $0.609(0.452-0.759)$ & \\
\hline & Temperature & $0.656(0.500-0.805)$ & \\
\hline
\end{tabular}

anthropogenic and natural processes (but see below). We can interpret these findings in terms of the influence of these different processes on different stages of the pathway to invasion by alien species (Blackburn et al., 2011).

The number of alien species on an island is a positive function of the number of species introduced ('colonization pressure') and the probability that an introduced species then establishes a viable population (Lonsdale, 1999; Lockwood et al., 2009). These processes are the equivalents of immigration and (one minus) extinction rates for native species. It is not obvious how native species richness would have a positive effect on colonization pressure, and so native richness is therefore most likely to act through effects on the probability that introduced species then successfully establish viable populations. There are at least two possible mechanisms for this. First, native species may directly determine opportunities for alien species establishment, such that islands with more native species also end up with more alien species. Second, the environment may influence the likelihood that both native species and alien species will persist in the same way, causing the positive relationship between the two to arise indirectly.

Direct effects of native species on opportunities for alien species establishment may include facilitation through shared mutualisms (Richardson et al., 2000). Rich plant assemblages may have promoted (or been promoted by) the existence of pollinators or mycorrhizal fungi that could then also be utilized by alien species (Richardson et al., 2000). In contrast, we can think of no good ecological reason why native bird species richness should directly promote establishment by alien bird species (Fig. 2). Our SEM models suggest that the indirect effects are unlikely to include area per se, temperature, isolation or precipitation. If these variables influenced both native and alien species richness, we would expect to observe direct paths between them and both richness variables (Fig. 2, Table 1). For plants, where the overwhelming role of habitat on alien species richness in a region has recently been emphasized (Chytrý et al., 2008a, 2008b), the most likely mechanism underlying the positive relationship at a large spatial scale is increasing habitat heterogeneity with area, which results in higher species numbers of both native and alien species. While indirect, this effect could appear as a direct path between native and alien plant richness in our models: indeed, if native plants do indeed respond to habitat heterogeneity, as strongly as argued (Chytrý et al., 2008a, 2008 b), then native plant richness would be an excellent proxy for it.

Further evidence of a role for habitat is provided by our subsequent analyses on the subset of 40 islands for which data on both plant and bird species richness are available. Our models of the full data set showed a direct effect of native bird richness on alien bird richness (Table 1, Fig. 2). In the subset analysis, this is replaced by a strong direct effect of native plant richness: indeed, native plant richness is the only direct positive predictor of alien bird species richness, and the only direct predictor of native bird richness (Table 2, Fig. 3). Links between native bird and native plant richness were present indirectly in the separate analyses of each taxon through the common effects of species-area relationships, latitudinal temperature gradients and distance from nearest mainland on native richness for each taxon (Table 1, Fig. 2). In the subset analyses, the direct effects of these variables on native bird richness are replaced by indirect effects through native plant richness, and their indirect effects on alien bird richness are retained. Previous studies have also shown positive relationships between native plant and native bird species richness over large spatial scales (e.g. Kissling et al., 2008; Jetz et al., 2009), which have been suggested to be a consequence of greater niche opportunities for birds provided by the increased structural complexity of richer plant assemblages (Kissling et al., 2008). Our analyses suggest that higher habitat heterogeneity, as indexed by native plant richness, may be a significant part of the reason why rich islands get richer in terms of both alien plant and alien bird richness, and indeed why some islands are richer than others in native bird species. 
The impact of human population size on alien species richness is more likely to act through its effect on immigration, via colonization pressure. For most alien taxa, we do not know how many species were introduced to a location but failed to establish: we lack this information for plants for the great majority of our islands (and for birds for many). Nevertheless, it is likely that colonization pressure is a positive function of the scale of human activities (e.g. trade volume, GDP), as these will increase the opportunities for accidental and deliberate introduction of species (Pyšek et al., 2010). Blackburn et al. (2008) have previously shown, for a subset of the data on alien birds analysed here, that colonization pressure was higher on islands with greater human population sizes. Human population size could also directly affect establishment probability, for example by increasing the niche space for human-commensal alien species (Chapple et al., 2012).

Interestingly, the effect of human population size disappears from our analyses of the subset of islands with both plant and bird richness data (Table 2, Fig. 3), seemingly as a result of the correlation with island area: area had an indirect effect on alien richness through human population size, as well as through native bird richness, in the original analysis (Table 1, Fig. 2). Immigration by alien species increased dramatically after European nations started to colonize other parts of the world in the middle of the 18th century (di Castri, 1989; Hulme, 2009; Blackburn et al., 2015). We therefore expected to see a positive effect of time since European colonization on alien species richness in our data. The SEMs identify no such effect, although for reasons that are unclear the associated GLMs do find that islands colonized more recently have more species of alien birds (Appendix S2). All of this suggests that immigration may be less important as a driver of alien species richness than establishment success (i.e. 1 - extinction rate), but the relative contributions will be difficult to determine with certainty in the absence of data on colonization pressure.

Our analysis of the full data set found that alien species richness was better fitted by separate SEMs for plants and birds, but there are nonetheless striking commonalities in the path structure for the two taxa (Fig. 2). The only two differences are negative direct effects of precipitation on alien bird species richness, and of area on plant species richness. The latter effect is weak, and is likely to be an artefact of inter-correlation between area, native species richness and human population size. The former effect shows that alien bird species richness is higher on drier islands. Rolett \& Diamond (2004) showed that islands in the Pacific with lower annual rainfall suffered higher deforestation in the period between first human and first European colonization, while Duncan et al. (2013) found that drier islands had suffered higher extinction rates in the native avifauna in this period. If these relationships generalize, they would imply that drier islands could have more opportunities for alien bird species to colonize, as a result of either habitat alteration or higher native bird species extinction.

We also found striking commonalities in the slopes of the species-area relationships for alien plants and birds $(z=0.24$ and 0.27 , respectively) and for native plants and birds $(z=0.39$ and 0.36 , respectively; Fig. 1). Thus, alien species richness increases with area at the same rate for both plants and birds, as does native species richness, although native richness increases with area more quickly. It is interesting that the processes that lead to plant and bird richness produce common relative increases with area for alien species, and higher but still common relative increases with area for native species. Given the time-scales involved, speciation and emigration can make only a trivial contribution to alien species richness in these data and, as noted above, the slopes of the alien species-area relationships must be determined just by immigration (colonization pressure) and extinction (via establishment success). These processes will be ongoing, as more alien species will be added to islands, while inevitably some will go extinct after shorter or longer residence times. The slopes of the alien species-area relationships are likely to change as a result, and it will be interesting to see whether or not they ultimately converge on native patterns. Our models imply that immigration and extinction act differently on alien plants and birds (Tables 1 \& 2), and that there is actually no direct positive effect of area on alien species richness, but that the outcome is nevertheless common speciesarea slopes. The precise influence of these processes would be fundamentally informed by data on colonization pressure. Nevertheless, our analyses suggest that not only do different processes underlie similar native and alien species-area relationships, but also that the same processes act differently to produce similar species-area relationships in different alien taxa. Common pattern is no guarantee of common process at any level of comparison.

\section{ACKNOWLEDGEMENTS}

We thank the handling editor and three anonymous referees for comments that greatly improved this work, and the Zoological Society of London and University of Adelaide for financial support. P.C. is an ARC Future Fellow (FT0991420). P.P. was supported by project no. 14-36079G, Centre of Excellence PLADIAS (Czech Science Foundation) and the long-term research development project RVO 67985939 (Academy of Sciences of the Czech Republic), and acknowledges support by a Praemium Academiae award from the Academy of Sciences of the Czech Republic.

\section{REFERENCES}

Blackburn, T.M., Cassey, P. \& Lockwood, J.L. (2008) The island biogeography of exotic bird species. Global Ecology and Biogeography, 17, 246-251.

Blackburn, T.M., Pyšek, P., Bacher, S., Carlton, J.T., Duncan, R.P., Jarošík, V., Wilson, J.R.U. \& Richardson, D.M. (2011) A proposed unified framework for biological invasions. Trends in Ecology and Evolution, 26, 333-339.

Blackburn, T.M., Dyer, E., Su, S. \& Cassey, P. (2015) Beyond the long list, or four things we (should) know about bird invasions. Journal of Ornithology, in press. DOI: 10.1007/s10336015-1155-Z 
Brown, J.H. \& Sax, D. (2004) An essay on some topics concerning invasive species. Austral Ecology, 29, 530-536.

Case, T.J. (1996) Global patterns in the establishment and distribution of exotic birds. Biological Conservation, 78, 69-96.

di Castri, F. (1989) History of biological invasions with special emphasis on the Old World. Biological invasions, a global perspective (ed. by J.A. Drake, F. di Castri, R.H. Groves, F.J. Kruger, M. Rejmánek and M. Williamson), pp. 1-30. John Wiley \& Sons, Chichester, UK.

Chapple, D.G., Simmonds, S.M. \& Wong, B. (2012) Can behavioral and personality traits influence the success of unintentional species introductions? Trends in Ecology and Evolution, 27, 57-64.

Chown, S.L., Gremmen, N.J.M. \& Gaston, K.J. (1998) Ecological biogeography of Southern Ocean islands: species-area relationships, human impacts, and conservation. The American Naturalist, 152, 562-575.

Chytrý, M., Jarošík, V., Pyšek, P., Hájek, O., Knollová, I., Tichý, L. \& Danihelka, J. (2008a) Separating habitat invasibility by alien plants from the actual level of invasion. Ecology, 89, 1541-1553.

Chytrý, M., Maskell, L.C., Pino, J., Pyšek, P., Vilà, M., Font, X. \& Smart, S.M. (2008b) Habitat invasions by alien plants: a quantitative comparison among Mediterranean, subcontinental and oceanic regions of Europe. Journal of Applied Ecology, 45, 448-458.

Duncan, R.P., Boyer, A. \& Blackburn, T.M. (2013) The magnitude and pattern of prehistoric bird extinctions across tropical Pacific Islands. Proceedings of the National Academy of Sciences USA, 110, 6436-6441.

Elton, C. (1958) The ecology of invasions by animals and plants. Methuen, London.

Ficetola, G.F. \& Padoa-Schioppa, E. (2009) Human activities alter biogeographical patterns of reptiles on Mediterranean islands. Global Ecology and Biogeography, 18, 214-222.

Grace, J.B. (2006) Structural equation modeling and natural systems. Cambridge University Press, Cambridge.

Hulme, P.E. (2008) Contrasting alien and native species-area relationships: the importance of spatial grain and extent. Global Ecology and Biogeography, 17, 641-647.

Hulme, P.E. (2009) Trade, transport and trouble: managing invasive species pathways in an era of globalization. Journal of Applied Ecology, 46, 10-18.

Jetz, W., Kreft, H., Ceballos, G. \& Mutke, J. (2009) Global associations between terrestrial producer and vertebrate consumer diversity. Proceedings of the Royal Society B: Biological Sciences, 276, 269-278.

Kalmar, A. \& Currie, D.J. (2006) A global model of island biogeography. Global Ecology and Biogeography, 15, 72-81.

Kissling, W.D., Field, R. \& Böhning-Gaese, K. (2008) Spatial patterns of woody plant and bird diversity: functional relationships or environmental effects? Global Ecology and Biogeography, 17, 327-339.

Kreft, H., Jetz, W., Mutke, J., Kier, G. \& Barthlott, W. (2008) Global diversity of island floras from a macroecological perspective. Ecology Letters, 11, 116-127.
Kueffer, C., Daehler, C.C., Torres-Santana, C.W., Lavergne, C., Meyer, J.-Y., Otto, R. \& Silva, L. (2010) A global comparison of plant invasions on oceanic islands. Perspectives in Plant Ecology, Evolution and Systematics, 12, 145-161.

Kummu, M. \& Varis, O. (2011) The world by latitudes: a global analysis of human population, development level and environment across the north-south axis over the past half century. Applied Geography, 31, 495-507.

Lockwood, J.L., Cassey, P. \& Blackburn, T.M. (2009) The more you introduce the more you get: the role of colonization pressure and propagule pressure in invasion ecology. Diversity and Distributions, 15, 904-910.

Long, J.D., Trussell, G.C. \& Elliman, T. (2009) Linking invasions and biogeography: isolation differentially affects exotic and native plant diversity. Ecology, 90, 863-868.

Lonsdale, W.M. (1999) Global patterns of plant invasions and the concept of invasibility. Ecology, 80, 1522-1536.

MacArthur, R.H. \& Wilson, E.O. (1967) The theory of island biogeography. Princeton University Press, Princeton.

McKinney, M.L. (2006) Correlated non-native species richness of birds, mammals, herptiles and plants: scale effects of area, human population and native plants. Biological Invasions, 8 , 415-425.

Mitchell, T.D. \& Jones, P.D. (2005) An improved method of constructing a database of monthly climate observations and associated high-resolution grids. International Journal of Climatology, 25, 693-712.

Pretto, F., Celesti-Grapow, L., Carli, E., Brundu, G. \& Blasi, C. (2012) Determinants of non-native plant species richness and composition across small Mediterranean islands. Biological Invasions, 14, 2559-2572.

Pyšek, P., Jarosik, V., Hulme, P.E. et al. (2010) Disentangling the role of environmental and human pressures on biological invasions across Europe. Proceedings of the National Academy of Sciences USA, 107, 12157-12162.

R Core Team (2014) R: a language and environment for statistical computing. R Foundation for Statistical Computing, Vienna, Austria.

Richardson, D.M., Allsopp, N., D’Antonio, C.M., Milton, S.J. \& Rejmanek, M. (2000) Plant invasions - the role of mutualisms. Biological Reviews, 75, 65-93.

Richardson, D.M., Pyšek, P. \& Carlton, J. (2011) A compendium of essential concepts and terminology in invasion ecology. Fifty years of invasion ecology. The legacy of Charles Elton (ed. by D.M. Richardson), pp. 409-420. John Wiley \& Sons Ltd, Oxford.

Rolett, B. \& Diamond, J. (2004) Environmental predictors of pre-European deforestation on Pacific islands. Nature, 431, 443-446.

Rosenzweig, M.L. (1995) Species diversity in space and time. Cambridge University Press, Cambridge.

Rosseel, Y. (2012) Lavaan: an R package for structural equation modeling. Journal of Statistical Software, 48, 1-36.

Sax, D., Brown, J.H. \& Gaines, S.D. (2002) Species invasions exceed extinctions on islands world-wide: a comparative study of plants and birds. The American Naturalist, 160, 766783. 
Sax, D.F. \& Gaines, S.D. (2005) The biogeography of naturalized species and the species-area relationship: reciprocal insights to biogeography and invasion biology. Conceptual ecology and invasions biology: reciprocal approaches to nature (ed. by M.W. Cadotte, S.M. McMahon and T. Fukami), pp. 449-479. Kluwer, Dordrecht.

Stohlgren, T.J., Barnett, D. \& Kartesz, J. (2003) The rich get richer: patterns of plant invasions in the United States. Frontiers in Ecology and the Environment, 1, 11-14.

Triantis, K.A., Guilhaumon, F. \& Whittaker, R.J. (2012) The island species-area relationship: biology and statistics. Journal of Biogeography, 39, 215-231.

Whittaker, R.J. (1998) Island biogeography. Oxford University Press, Oxford.

Whittaker, R.J., Triantis, K.A. \& Ladle, R.J. (2008) A general dynamic theory of oceanic island biogeography. Journal of Biogeography, 35, 977-994.

Zhang, J., Kissling, D.W. \& He, F. (2013) Local forest structure, climate and human disturbance determine regional distribution of boreal bird species richness in Alberta, Canada. Journal of Biogeography, 40, 1365-2699.

\section{SUPPORTING INFORMATION}

Additional supporting information may be found in the online version of this article at the publisher's web-site.

Appendix S1 A table of data and associated sources. Appendix S2 Supporting analyses.

\section{BIOSKETCHES}

Tim Blackburn is an ecologist with interests in human-mediated biological invasions, extinction and other topics relating to the large-scale distribution and abundance of species. He mainly works on birds.

Steve Delean is an environmental biostatistician and wildlife ecologist.

Phill Cassey is an invasion ecologist with interests in the distribution, transport and trade of alien species, particularly vertebrates.

Editor: Richard Field 